\title{
Divergence of Borrelia burgdorferi sensu lato spirochetes could be driven by the host: diversity of Borrelia strains isolated from ticks feeding on a single bird
}

Nataliia Rudenko ${ }^{1,2^{*}+}$, Maryna Golovchenko ${ }^{1,2 \dagger}$, Natalia M Belfiore ${ }^{3}$, Libor Grubhoffer ${ }^{1,4}$ and James H Oliver $\mathrm{Jr}^{2}$

\begin{abstract}
Background: The controversy surrounding the potential impact of birds in spirochete transmission dynamics and their capacity to serve as a reservoir has existed for a long time. The majority of analyzed bird species are able to infect larval ticks with Borrelia. Dispersal of infected ticks due to bird migration is a key to the establishment of new foci of Lyme borreliosis. The dynamics of infection in birds supports the mixing of different species, the horizontal exchange of genetic information, and appearance of recombinant genotypes.

Methods: Four Borrelia burgdorferi sensu lato strains were cultured from Ixodes minor larvae and four strains were isolated from Ixodes minor nymphs collected from a single Carolina Wren (Thryothorus ludovicianus). A multilocus sequence analysis that included $16 \mathrm{~S}$ rRNA, a 5S-23S intergenic spacer region, a 16S-23S internal transcribed spacer, flagellin, $p 66$, and $\operatorname{osp} C$ separated 8 strains into 3 distinct groups. Additional multilocus sequence typing of 8 housekeeping genes, cIpA, cIpX, nifS, pepX, pyrG, recG, rplB, and uvrA was used to resolve the taxonomic status of bird-associated strains.

Results: Results of analysis of 14 genes confirmed that the level of divergence among strains is significantly higher than what would be expected for strains within a single species. The presence of cross-species recombination was revealed: Borrelia burgdorferi sensu stricto housekeeping gene nifs was incorporated into homologous locus of strain, previously assigned to B. americana.

Conclusions: Genetically diverse Borrelia strains are often found within the same tick or same vertebrate host, presenting a wide opportunity for genetic exchange. We report the cross-species recombination that led to incorporation of a housekeeping gene from the B. burgdorferi sensu stricto strain into a homologous locus of another bird-associated strain. Our results support the hypothesis that recombination maintains a majority of sequence polymorphism within Borrelia populations because of the re-assortment of pre-existing sequence variants. Even if our findings of broad genetic diversity among 8 strains cultured from ticks that fed on a single bird could be the exception rather than the rule, they support the theory that the diversity and evolution of LB spirochetes is driven mainly by the host.
\end{abstract}

Keywords: Borrelia burgdorferi sensu lato, Ixodes minor, Bird migration, Bird reservoir host, Multilocus sequence analysis, Multilocus sequence typing, Recombinant genotypes, Southeastern United States

\footnotetext{
* Correspondence: natasha@paru.cas.cz

${ }^{\dagger}$ Equal contributors

'Biology Centre AS CR, Institute of Parasitology, České Budějovice 37005,

Czech Republic

${ }^{2}$ James H Oliver, Jr Institute of Coastal Plain Sciences, Georgia Southern

University, Statesboro, GA 30460-8056, USA

Full list of author information is available at the end of the article
}

C Biomed Central

(c) 2014 Rudenko et al.; licensee BioMed Central Ltd. This is an Open Access article distributed under the terms of the Creative Commons Attribution License (http://creativecommons.org/licenses/by/2.0), which permits unrestricted use, distribution, and reproduction in any medium, provided the original work is properly cited. The Creative Commons Public Domain Dedication waiver (http://creativecommons.org/publicdomain/zero/1.0/) applies to the data made available in this article, unless otherwise stated. 


\section{Background}

The list of hosts for Ixodid ticks that serve as reservoirs for Borrelia currently includes several hundred vertebrate species comprised of mammals, reptiles and birds [1]. The controversy surrounding the ability of birds to serve as reservoirs, and the impact of birds in spirochete transmission dynamics has existed for quite a long time [2-5]. Recent findings indicate that the majority of analyzed bird species are able to infect larval ticks with Borrelia [1,6-8]. However, reservoir capabilities of different bird species vary, as they do in mammals [9]. Infection rates in ticks removed from birds is comparable to those removed from mammals and in some cases reaches as much as $43.5 \%[9,10]$. At least 80 bird species parasitized by Ixodid ticks are recognized in North America $[6,11]$. Additionally, 300 seabird species are involved in a global transmission cycle [12]. The role of birds in the spread of infected ticks is now well documented [12-14]. Earlier estimations have revealed, for example, that birds disperse 50 to 175 million Ixodes scapularis ticks across Canada each spring [15]. Today, the reservoir role of various bird species, especially those of ground-nesting and ground-foraging birds, such as thrushes, blackbirds, robins, wrens, nightingales, blue throats and pheasants, is unanimously recognized. They transport infected ticks and the pathogens, and thus serve as efficient amplifying reservoirs of some spirochete species worldwide [10,15-17].

Nineteen named spirochete species from the Borrelia burgdorferi sensu lato (sl) complex are recognized around the world [18-34]. The development and wide usage of new techniques such as multi locus sequence analysis (MLSA) [28] and multi locus sequence typing (MLST) [35] resulted in the description of 6 new spirochete species in the past 5 years, B. yangtze [20], B. carolinensis [31], B. bavariensis [26], B. americana [32], $B$. kurtenbachii [25] and B. finlandensis [34]. Divergences among known Borrelia species reflect ecological, evolutionary, epidemiological, adaptive and geographical differences. Certain Borrelia species are more common to mammalian, avian or reptilian hosts [36,37], for example. Today, all recognized B. burgdorferi sl species can be divided into four ecological groups: a) species adapted to mammals (i.e. B. afzelii, B. carolinensis); b) species adapted to birds (i.e. B. garinii, B. americana); c) species adapted to reptilian hosts (i.e. B. lusitaniae) or d) species with no specialized hosts (i.e., B. burgdorferi ss). Such separation is not, however, absolute. Occasionally, different Borrelia species have been detected in ticks found on "inappropriate hosts", whose complement normally eliminates mentioned species during the blood meal.

The key determinant of spirochete/host interaction has been associated with the complement regulatoracquiring surface proteins encoded by members of the erp gene family [36,38-40]. The general function of the erp gene family is to bind the host-derived complement control proteins in a species-specific pattern [41]. The erp genes represent prophage genomes [42] that are employed in reshuffling of genetic material among Borrelia strains, holding the key to the adaptive radiation of Borrelia species [43]. The dynamics of infection in host populations will determine the opportunity for mixing of different genotypes, allowing the horizontal gene transfer of genetic material, and triggering genetic changes in the Borrelia complex [43].

Kurtenbach and colleagues suggested that the diversity and evolution of LB spirochetes cannot be attributed to tick diversity, but appears to be driven mainly by the host [36]. The diversity of Borrelia species associated with rodents, which have migration rates of 200-300 meters per generation, is much lower than in species associated with birds [33]. This conclusion is also supported by the complex population structure of Borrelia garinii in subarctic Eurasia. B. garinii is thought to be genetically and antigenically the most heterogeneous species among $B$. burgdorferi sl complex because of its association with passerine and marine birds [15]. Borrelia has the recombination system needed for genetic exchange. Genetically diverse strains of Borrelia are often found within the same tick or same vertebrate host and this gives a wide opportunity for genetic exchange [44-46].

How does the genomic diversity within a Borrelia population originate and how is it maintained? Is the appearance of a new species determined by selective pressure from the vertebrate immune response, point mutations or horizontal gene transfer among sympatric genomes? Here we present the analysis of a small group of 8 single-birdassociated Borrelia strains primarily assigned to B. americana. Combined MLSA and MLST analyses revealed that level of divergence among 8 strains is higher than what would be expected for strains within a single species. We report the cross-species recombination that led to incorporation of the B. burgdorferi ss housekeeping gene nifS into the homologous locus in strain SCW-30 h. Our results support the hypothesis that recombination maintains a majority of sequence polymorphism within $B$. burgdorferi sl populations [47].

\section{Methods}

\section{Ticks and Borrelia}

Eight Borrelia strains were isolated from two developmental stages of the hard tick Ixodes minor collected from a single Carolina Wren (Thryothorus ludovicianus) captured at the Wedge Plantation, Charleston County, South Carolina, USA, in November of 1994. Strains SCW-30a, SCW-30b, SCW-30c and SCW-30d, were isolated each from an individual pool of $3 \mathrm{I}$. minor larvae. Strains SCW-30e, SCW-30f, SCW-30 g and SCW-30 h 
were isolated each from an individual I. minor nymph. Conditions for Borrelia cultivation were described elsewhere $[30,31]$.

\section{Primers used in this study}

Previously described PCR primer sets were used for amplification of 5S-23S IGS [48], 16S rRNA [49], flagellin [50], p66 [50], ospC [51] and 16S-23S ITS [51]. The MLST scheme was used for amplification and analysis of 8 housekeeping genes: $\operatorname{clp} A, \operatorname{clp} X$, nifS, pepX, pyrG, recG, $r p l B$ and $u v r A$ [52]. The amplification conditions for all selected genomic loci were strictly as described.

\section{General analysis of Borrelia isolates}

DNA purification, PCR amplification, sequencing and sequence analysis were conducted according to our previously described protocol [31] and MLST scheme developed by Margos et al., 2008 [52]. Total DNA from cultured spirochetes was purified using the DNeasy Blood and Tissue kit (Qiagen, USA). The MasterTaq Kit (Eppendorf, Germany) was used for amplification of selected loci. The purified PCR products were submitted for direct sequencing to the University of Washington High-Throughput Genomic Unit (Seattle, USA). Sequencing was conducted in both directions, using the same primers that were used for amplification of each locus. Sequences determined in this study have been deposited into GenBank.

The restriction fragment length polymorphism (RFLP) analysis of borrelia 5S-23S IGS and flagellin gene was done in silico using the free software available at http:// insilico.ehu.es [53] as it was previously described [31]. The 5S-23S IGS was digested with MseI and DraI restriction endonucleases; flagellin gene was digested with HapII, HhaI, HincII, CelII, and DdeI. Obtained RFLP patterns were compared with patterns already published $[13,47,54]$.

\section{Phylogenetic analysis}

We sequenced 14 genomic loci for each Borrelia strain: i.e., 16S rRNA, a 5S-23S IGS, a 16S-23S ITR, flagellin, $p 66, \quad \operatorname{sp} C$ and housekeeping genes, $\operatorname{clp} A, \operatorname{clpX}$, nifS, pepX, pyrG, recG, rplB, and uvrA. Twelve loci were ultimately included in the phylogenetic analysis; osp $C$ and 16S-23S ITS were excluded due to the high levels of polymorphism and recombination.

Sequences were aligned using Clustal X [55]. Data were evaluated for fit to 24 evolutionary models using MrModeltest [56]. The most-parameterized model that best fits the data at each locus was selected and evaluated by either the likelihood ratio test or Akaike Information Criterion [57]. Phylogenetic analyses were performed using Bayesian reconstruction methods, with the underlying model of evolution set to the chosen model in the program
MrBayes 3.1. Selected models were: $\mathrm{GTR}+\mathrm{G}$ for $\operatorname{clp} A$ (579 bp) and nifS (564 bp) loci, GTR + I + G for clpX (624 bp), pepX (570 bp), pyrG (603 bp), recG (651 bp), rplB (624 bp) and $u v r A(570 \mathrm{bp}), \mathrm{HKY}+\mathrm{G}$ for $5 \mathrm{~S}-23 \mathrm{~S}$ IGR (275 bp), HKY + I for flagellin gene (487 bp), and GTR + I for $p 66$ (315 bp) and 16S rRNA (1363 bp) [58,59]. The Markov Chain Monte Carlo (MCMC) analysis was run for $10 \times 10^{6}$ generations, sampling trees every 1000 generations, using 4 Markov chains (default heating values). Stationarity of the MCMC was evaluated using the "Are We There Yet" (AWTY) software [60] that plots the cumulative posterior probabilities for each tree. Two to three thousand burn-in trees generated before the point, at which these values stabilized, were discarded. The fifty percent majority rule consensus tree for the estimated posterior distribution of trees (with burn-in trees truncated) was assembled for each locus, using MrBayes [59]. The consensus trees for each of twelve genes (excluding ospC and 16S-23S ITS) were not congruent, and thus an overall pattern of relatedness could not be inferred using these gene-trees alone.

The most common approach to inferring relationships across multiple genetic loci is to combine outcomes of individual gene trees into multi-locus analysis. The Bayesian estimation of concordance among gene trees (BUCKy) approach [61], which makes no assumptions about the source of reticulation in gene tree histories was used here. BUCKy uses, as input data, the complete tree files generated by the Bayesian analysis of each individual locus, in the format generated by MrBayes [59]. BUCKy generates a sample of gene trees from the joint distribution of gene trees, from which concordance factors (CFs) are estimated with credibility intervals. The CF ranges from 0.0 to 1.0. BUCKy implements a consensus method based on unrooted quartets and which consistently identifies the species tree [62]. We ran BUCKy at several levels of $\alpha$ to evaluate how much effect choice of this parameter value would have on the results. The final analysis selected for use was run with an $\alpha$ of 1 , a reasonable intermediate between 0 and infinity [63], using 4 heated chains in the MCMC analysis.

\section{Nucleotide sequence accession numbers}

Sequences determined in this study have been deposited into GenBank and given the indicated accession numbers (numbers for each isolate are given for sequenced genomic loci in the following order: 5S-23S intergenic spacer, $16 \mathrm{~S}$ rRNA, flagellin, p66, 16S-23S ITS, and ospC): HM802215, HM802221, HM802227, HM802233, HQ012507 and HM85 2908 for SCW-30a; HM802216, HM802222, HM802228, HM802234, HQ012502 and HM852909 for SCW-30b; HM 802217, HM802223, HM802229, HM802235, HQ012503 and HM852910 for SCW-30c; HM802218, HM802224, HM802230, HM802236, HQ012504 and HM852911 for 
SCW-30d; HM140981 and HM146415 for 16S-23S intergenic spacer and $o s p C$ gene of SCW-30e; HM802219, HM802225, HM802231, HM802237, HQ012505 and HM 852912 for SCW-30f; HM140982 and HM146416 for 16S$23 \mathrm{~S}$ intergenic spacer and $o s p C$ gene of SCW-30 g and HM802220, HM802226, HM802232, HM802238, HQ012 506 and HM852913 for SCW-30 h. Accession numbers for 5S-23S IGS, 16S rRNA, flagellin and p66 of isolates SCW30e and SCW-30 g were presented earlier in Rudenko et. al, 2009 [32]. Sequences of housekeeping genes of all strains from SCW-30 group were submitted as 8 sets to the PopSet database and are accessible in GenBank using Entrez PopSet numbers: 358009204 for $c l p A$ genes, 358009220 for $c l p X$ genes, 358009236 for nifS genes, 358009252 for $p e p X$ genes, 358009268 for pyrG genes, 358009284 for recG genes, 358009300 for $r p l B$ genes and 358009316 for $u v r A$ genes.

\section{Control strains of Borrelia burgdorferi sensu lato species used in analysis}

The sequences of corresponding genomic loci of following control strains available in GenBank were used in the phylogenetic analyses: $B$. burgdorferi sensu stricto B31; B. afzelii VS461; B. americana SCW41; B. andersonii 21133; B. bavariensis PBi; B. bissettii DN127; B. californiensis CA443; B. carolinensis SCW22; B. garinii 20047; B. japonica HO14; B. kutrenbachii 25015; B. lusitaniae PotiB2; B. sinica CMN3; B. spielmanii A14S; B. tanukii HK501; B. turdi Ya501; B. valaisiana VS116; B. yangtze R5 and genomospecies 2 CA-2.

\section{Results}

The eight strains isolated from Ixodes minor larvae and nymphs collected from a single Carolina Wren were analyzed previously at six genomic loci, 5S-23S IGS, $16 \mathrm{~S}$ rRNA, flagellin, p66, 16S-23S ITS and ospC [30]. At all six loci 8 strains clustered as larvae-associated "b/c/d" group (SCW-30b, SCW-30c, and SCW-30d), nymphassociated "e/f/g" group (SCW-30e, SCW-30f, and SCW-30 g) and standalone nymph-originated SCW-30 h strain. In a previous study, strains SCW-30e and SCW$30 \mathrm{~g}$ were assigned to $B$. americana [32]. In the same study strain SCW-30f was also assigned to this species by preliminary analysis of the $16 \mathrm{~S}$ rRNA gene [32]. The larvae-originated strain SCW-30a alternately clustered with the $B$. americana "e/f/g" and "b/c/d" clusters, depending on the locus analyzed.

PCR of the 5S-23S IGS locus resulted in amplicons of 3 different sizes across the 8 samples: 254 bp for SCW-30a, SCW-30e, SCW-30f and SCW-30 g, 253 bp for SCW-30 h and 225 bp for SCW-30b, SCW-30c and SCW-30d strains. MseI and DraI RFPL patterns of SCW-30e, SCW-30f, SCW-30 g and SCW-30 h corresponded to those described for B. americana subgroup A and B [32]. The RFLP pattern found at this locus in SCW-30b, SCW-30c and SCW-30d could not be associated with any known Borrelia species and represents four MseI restriction fragments, 107, 52, 38, and $28 \mathrm{bp}$, and three DraI restriction fragments, 144,53 , and $28 \mathrm{bp}$. The DraI RFLP pattern for SCW-30a was identical to that of $B$. americana, but the MseI pattern in that strain was different and contained 5 fragments of $107,80,38,16$, and $13 \mathrm{bp}$ instead of the 6 specific to $B$. americana [32].

In silico RFLP analysis of the 488 bp flagellin gene involved sequence digestion with HapII, HhaI, HincII, CelII, and DdeI restriction endonucleases. Amplicons of SCW30e, SCW-30f, SCW-30 g and SCW-30 h revealed the pattern specific for $B$. americana [32]. RFLP patterns in SCW-30a, SCW-30b, SCW-30c and SCW-30d at this locus were identical, but unknown, resulting in two fragments in case of restriction with DdeI only (338 and150 bp).

In the $p 66$ locus, SCW-30b, SCW-30c and SCW-30d strains showed $99.7-100 \%$ similarity among themselves only; SCW-30e, SCW-30f and SCW-30 g strains revealed $99.0-100 \%$ similarity to the $B$. americana type strain and to SCW-30 h; strain SCW-30a was 98.198.7\% similar to both the "b/c/d" and the "e/f/g" groups of strains.

All 8 strains were $99.6-100 \%$ similar on the 1,316 bp amplicon of $16 \mathrm{~S}$ rRNA.

Larvae-originated SCW-30b, SCW-30c and SCW-30d were $100 \%$ identical at 16 S-23S ITS locus. Previously identified as B. americana, SCW-30e, SCW-30f, SCW$30 \mathrm{~g}$, and SCW-30 h showed $99.88-100 \%$ similarity among themselves. Strain SCW-30a showed the lowest similarity, $85.63-88.08 \%$, to the rest of strains at this locus.

Strains SCW-30a, SCW-30b, SCW-30c and SCW-30d were identical at the $\operatorname{sp} C$ locus and showed no significant similarity to known $\operatorname{ssp} C$ types. The $\operatorname{sp} p$ genes of SCW-30e, SCW-30f and SCW-30 g were 97-99\% similar to those of other B. americana strains. SCW $-30 \mathrm{~h} \operatorname{sspC}$ was $100 \%$ identical to one of $B$. americana type strain $\mathrm{SCW}-41^{\mathrm{T}}$ and revealed the high similarity to $\operatorname{osp} C$ allele $\mathrm{B}$ of $B$. burgdorferi ss strains that are widely distributed in southeastern United States [64].

Results of analysis of 6 genes using MLSA scheme from our previous studies [31,32] was insufficient to resolve the taxonomic status of the strains from SCW-30 group revealing apparent recombination of genetic material among fast evolving genomic loci.

Sequences of 8 housekeeping genes $\operatorname{clp} A, \operatorname{clp} X$, nifS, pepX, pyrG, recG, rplB and $u v r A$ from 8 SCW-30 strains were compared with the allelic profiles using "virtual isolate collections centers" [35] from the online MLST database (www.mlst.net) [65]. The MLST database currently contains data for approximately 1,200 Borrelia strains comprising most of the described B. burgdorferi sl species from all over the world which have been 
resolved into $>300$ sequence types (ST's) [50]. We found that only strains SCW-30f and SCW-30 g carried the same alleles as the type strain of $B$. americana SCW $-41^{\mathrm{T}}$. Strain SCW-30e was broadly variable at the housekeeping loci (Table 1). The similarity of strains SCW-30b, SCW-30c and SCW-30d were below the cut-off value for species assignment at 4 of the 8 loci analyzed, pepX, pyrG, recG and uvrA (Table 2). The divergence of strain SCW-30 h was the highest among the group. Cross-species recombination was detected with this method of comparison, and seemed to be the result of the incorporation of a B. burgdorferi ss housekeeping gene, nifS, into the homologous locus of strain SCW-30 h. This allele is specific to B. burgdorferi ss strains widely distributed in the United States and in Canada (borrelia.mlst.net).

Eight concatenated housekeeping gene sequences from each SCW-30 strain (2,752 bp/strain) were aligned with 18 available in MLST database sequence types (ST) for type strain of known Borrelia species and genomospecies 2: ST1 (B. burgdorferi ss), ST64 (B. lusitaniae), ST70 (B. afzelii), ST83 (B. garinii), ST84 (B. bavariensis), ST95 (B. valaisiana), ST152 (B. yangtze), ST159 (B. spielmanii), ST272 (B. bissettii), ST280 (B. kurtenbachii), ST388 (B. andersonii), ST447 (B. californiensis), ST449 (B. americana), ST450 (B. carolinensis), ST453 (B. japonica), ST454 (B. tanukii), ST455 (B. turdii) (not shown). Genetic distance between SCW-30 group and all known species, except B. americana, was significant and far below the cut-off value of 0.170 determined by MLST scheme [52]. Sequence pair distance analysis revealed that strains SCW-30b, SCW-30c and SCW-30d were identical among themselves. Strains SCW30f and SCW-30 g were identical between themselves and definitely belong to $B$. americana (Table 2). The cut-off value 0.170 for species determination for this scheme was exactly the one that showed genetic distance between SCW-30b, SCW-30c and SCW-30d and B. americana strains. Based on analysis of concatenated sequences strain SCW-30 h represents a species distinct from that of SCW30a, SCW-30b, SCW-30c and SCW-30d. Analysis based on individual housekeeping genes put SCW-30 h outside of $B$. americana group (Table 1).

Significant incongruence was observed in results of analysis of fast evolving and slow evolving genes or noncoding genomic loci of SCW-30a strain. This could reflect the recent recombination or re-assortment of sequence variations within SCW-30 group or another Borrelia population that we did not detect in this study. Analysis of concatenated housekeeping genes assigned SCW-30a to $B$. americana species, though as rather highly divergent member. This conclusion might not be definite yet.

\section{Phylogenetic analysis}

The resulting population and consensus trees from the concordance analysis are shown in Figure 1. This is a combined analysis of fast and slow evolving, plasmid- and chromosomally-located genes and non-coding regions of $8 \mathrm{SCW}-30$ strains (excluding $\operatorname{osp} \mathrm{C}$ and 16S-23S ITS). The reported sample-wide concordance factors on the tree (CFs) are not comparable to posterior probabilities or bootstrap support values, and thus they are not interpreted as a normal support statistic would be. They are used as information about the status of the clade in question. Values around 0.5 and above indicate that most of the trees in the sample set contain that clade, and that there is no predominant discordant clade configuration.

The type strain of B. americana clusters with SCW-30e forming a very well-supported clade, indicating that these are likely very similar or very recently diverged strains. SCW-30f and SCW-30 g cluster together with moderate

Table 1 Genetic divergence among individual housekeeping genes of SCW-30 strains and estimated allelic profiles

\begin{tabular}{|c|c|c|c|c|c|c|c|c|}
\hline & clpA & clpX & nifS & pepX & pyrG & recG & $r p / B$ & uvrA \\
\hline $\mathrm{SCW}-41^{\mathrm{Ta}}$ & $176^{c}$ & 141 & 127 & 154 & 159 & 159 & 136 & 150 \\
\hline SCW-33 & 175 & 140 & 126 & 153 & 158 & 158 & 135 & 149 \\
\hline SCW-30a & 175 (98.4\%) & 141 (99.7\%) & 127 (99.3\%) & 154 (98.6\%) & 159 (99.7\%) & 159 (99.1\%) & 136 (99.2\%) & 150 (99\%) \\
\hline SCW-30b & 175 (98.4\%) & 141 (99\%) & 127 (99.3\%) & 153 (97.5\%) & 159 (97.8\%) & 159 (98.2\%) & 136 (99.5\%) & 150 (98\%) \\
\hline SCW-30c & 175 (98.4\%) & 141 (99\%) & 127 (99.3\%) & 153 (97.5\%) & 159 (97.8\%) & 159 (98.2\%) & 136 (99.5\%) & 150 (98\%) \\
\hline SCW-30d & 175 (98.4\%) & 141 (99\%) & 127 (99.3\%) & 153 (97.5\%) & 159 (97.8\%) & 159 (98.2\%) & 136 (99.5\%) & 150 (98\%) \\
\hline SCW-30e & 175 (98.4\%) & 141 (99.8\%) & 127 (98.6\%) & 154 & 159 (98.2\%) & 159 (98.5\%) & 136 (99.8\%) & 150 (98\%) \\
\hline SCW-30f & 176 (99.7\%) & 141 & 127 & 154 & 159 & 159 & 136 & 150 \\
\hline SCW-30 g & 176 (99.7\%) & 141 & 127 & 154 & 159 & 159 & 136 & 150 \\
\hline SCW-30 h & 176 (99.7\%) & 141 (98.4\%) & $3(98.4 \%)$ & 154 (98.9\%) & 159 (97.5\%) & 159 (97.5\%) & 135 (99.5\%) & 150 (98\%) \\
\hline
\end{tabular}

The percentage of identity of housekeeping genes of SCW-30 strains to the closest alleles available in MLST database are presented in the Table 1.

SCW $-41^{\text {Ta }}$ is a type strain of Borrelia americana and represents subgroup A (ATCC BAA-1877; DSM 22541).

$\mathrm{SCW}-33^{\mathrm{b}}$ represents $B$. americana subgroup $\mathrm{B}$.

$176^{\mathrm{C}}$-unique allele numbers of housekeeping genes in MLST database. Strain allelic profile is a composition of 8 numbers presented in a single row. Marked in bold are values that are below or equal to a cut-off value of 0.170 determined for the MLST scheme based on eight chromosomally located housekeeping genes [26]. 
Table 2 Genetic divergences among SCW-30 strains based on 8 concatenated housekeeping genes

\begin{tabular}{lccccccccc}
\hline & SCW-30a & SCW-30b & SCW-30c & SCW-30d & SCW-30e & SCW-30f & SCW-30 g & SCW-30 h & SCW-41 \\
\hline SCW-30a & & 98,9 & 98,9 & 98,9 & 98,5 & 99,1 & 99,1 & $\mathbf{9 8}$ & 99,1 \\
SCW-30b & 1,1 & & 100 & 100 & 98,5 & $\mathbf{9 8 , 3}$ & $\mathbf{9 8 , 3}$ & $\mathbf{9 7 , 7}$ & $\mathbf{9 8 , 3}$ \\
SCW-30C & 1,1 & 0 & & 100 & 98,5 & $\mathbf{9 8 , 3}$ & $\mathbf{9 8 , 3}$ & $\mathbf{9 7 , 7}$ & $\mathbf{9 8 , 3}$ \\
SCW-30d & 1,1 & 0 & 0 & & 98,5 & $\mathbf{9 8 , 3}$ & $\mathbf{9 8 , 3}$ & $\mathbf{9 7 , 7}$ & $\mathbf{9 8 , 3}$ \\
SCW-30e & 1,5 & 1,5 & 1,5 & 1,5 & & 98,9 & 98,9 & $\mathbf{9 8 , 2}$ & 98,9 \\
SCW-30f & 0,9 & 1,7 & 1,7 & 1,7 & 1,1 & & 100 & 98,4 & 99,9 \\
SCW-30 g & 0,9 & 1,7 & 1,7 & 1,7 & 1,1 & 0 & & 98,4 & 99,9 \\
SCW-30 h & 2 & 2,4 & 2,4 & 2,4 & 1,8 & 1,6 & 1,6 & & \\
SCW-41 & 0,9 & 1,7 & 1,7 & 1,7 & 1,7 & 0,1 & 0,1 & & 1,7
\end{tabular}

SCW- $41^{\top}$ is a type strain of Borrelia americana (ATCC BAA-1877; DSM 22541)

Marked in bold are values that are below or equal to a cut-off value of 0.170 determined for the MLST scheme based on eight chromosomally located housekeeping genes [26].

support, and together with B. americana and SCW-30e form a moderately well-supported clade "e/g/f". Strains SCW-30b, SCW-30c and SCW-30d form an extremely well supported clade, with a concordance factor above $90 \%$. The arrangement of SCW-30c and SCW-30d within the clade is less well supported, but the three strains clearly share histories strongly. SCW-30a clusters with SCW-30b, SCW-30c and SCW-30d, but with only moderate support forming a clade "a/b/c/d". SCW-30 h is located outside the "a/b/c/d" and "e/g/f" clades and its placement is moderately well supported ( $>67 \%$ but with a wide confidence interval).

\section{Discussion}

Comparison of SCW-30 strains with the control samples makes it clear that either there is ongoing changes among these strains, or that the divergence is very recent. The concordance among gene trees for control samples as separate and distinct clades is extremely high. However, concordance among gene trees for most of the clusters of SCW-30 strains is less clear. The clades that stand out as distinct are B. americana $+\mathrm{SCW}-30 \mathrm{e}$, than SCW-30b, SCW-30c, SCW-30d and, SCW-30 h. Branch lengths make it clear that genetic divergence of these strains is as great as divergence among other clearly designated distinct species. Traditional rules of Borrelia taxonomy would support the claim that some of SCW-30 strains could have the status of new species, distinct from $B$. americana. However, the ongoing changes (from whatever source) and incongruence makes it difficult to determine if new species status should be assigned to selected SCW-30 strains, even after extended molecular analysis of 14 genomic loci of different functionality, which is the biggest known attempt other than the whole genome sequencing. The support for any cluster at this point would be ambiguous.

Local Borrelia populations show established biogeographic structure, often including a significant number

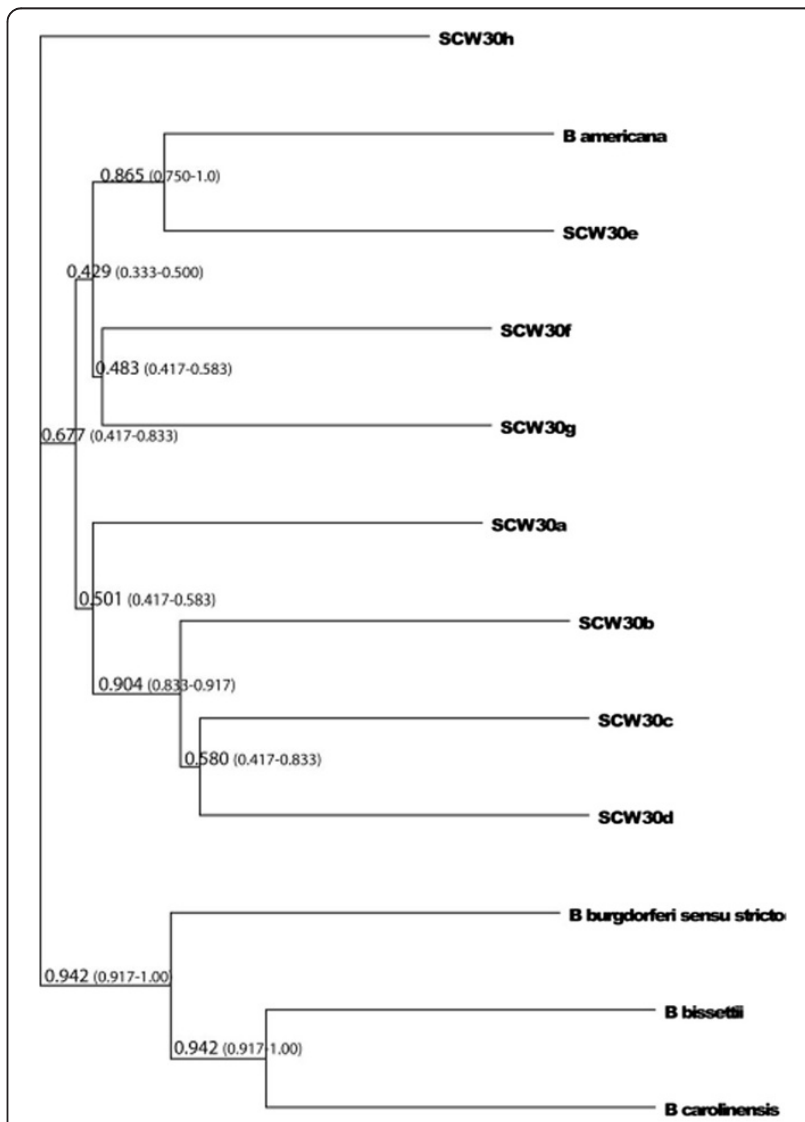

1

Figure 1 Population tree of control Borrelia species and strains from SCW-30 group. Fast and slow evolving plasmid and chromosome located genes and non-coding region were included into the analysis. Bayesian concordance analysis was conducted using BUCKy [63] with a value of 1.0 for a, the parameter that summarizes prior expectations of the amount of concordance among gene trees. Each split is annotated with the posterior mean sample-wide concordance factor and its 95\% credibility interval. The concordance factor shows the proportion of the sample trees for which the split is true, ranging from 0.0-1.0. Branch lengths are in coalescence units. 
of distinct genomic groups and are highly diverse, often co-infect a single tick species or vertebrate host, and coexist in sympatric fashion [44,51,66-68]. MLST and whole genome sequencing of different Borrelia species has confirmed that horizontal exchange of genetic information is pervasive across the Borrelia genome, occurs frequently between different genospecies and is more frequent than point mutations [47]. The origin of the high diversity within a local Borrelia population is an open subject for discussion. Several hypotheses have been proposed and one suggests that the diversity and evolution of LB spirochetes appears to be driven mainly by the host [36], and distinct clonal groups are maintained by host specialization [44,69].

The importance of birds as reservoir hosts in the ecology of LB around the world is clearly recognized today. Birds are capable of transmitting the highest number of known genotypes, albeit at different frequencies [70]. Multiple studies have confirmed the involvement of different bird species in the enzootic maintenance of $B$. burgdorferi sl species in endemic areas $[1,10,17,40,54,71-78]$. Migratory passerine birds have been shown to be responsible for spreading Borrelia infected ticks within and between continents, establishing new foci for Lyme borreliosis [13,16,66,77-79].

Passerines are parasitized by both tick larvae and nymphs [80]. Typically, in the northern populations of $I$. scapularis and I. ricinus, infected nymphs transmit spirochetes to hosts that subsequently infect larval ticks. Since the discovery of Lyme borreliosis, the evidences of transovarial transmission of $B$. burgdorferi sl were presented and it was believed until recently that larval ticks may, infrequently, obtain the LB spirochete by transovarial transmission, with the prevalence of less that 1\% [81]. A recent literature review and observations have indicated that the transovarial transmission of the LB spirochete does not exist and was confused for years with the transovarial transmission of the antigenically and phylogenetically related Borrelia miyamotoi [82]. This fact leaves the only possibility for larvae to get infected with LB spirochete - the host. The relatively high prevalence of Borrelia-infected larvae collected from birds (from 3$3.1 \%[82,83]$ to $29 \%[14,83])$ indicates that they became infected while feeding on birds. When the spirochetes persist in a bird for a long time, birds become an amplifier of $B$. burgdorferi sl, transmitting the pathogen to a greater number of ticks. Larvae maintain infection through the molt, giving rise to a new population of infected host-seeking nymphs. The efficiency of this cycle leads to a high prevalence of $B$. burgdorferi sl infection in questing nymphs, and a high public health risk in the region [84].

The transmission of $B$. burgdorferi sl between ticks and vertebrate hosts is a complex process. The interaction of
Borrelia with the alternative pathway of the host's complement system is considered to be the key determinant of spirochete-host association [36,85-88]. As part of the innate immune system, the alternative pathway can rapidly respond to pathogens before antibodies are generated [36]. A clear pattern of resistance or sensitivity of spirochetes to host complement is correlated with patterns of transmissibility. Spirochetes that are sensitive to the complement of a particular species are lysed by the host complement in the gut of the feeding tick before they are transmitted to the hosts. Selective survival of B. burgdorferi sl in the tick midgut, depending on the source of serum and the genetic background of the bacteria, can manifest itself in the selective replacement of Borrelia strains during the tick life cycle [36]. The high diversity of local spirochete populations has often been connected to host specialization or to the coexistence of multiple genospecies in the region with pervasive recombination among sympatric genomes [11,47]. Multiple-niche polymorphism, a form of balancing selection, can maintain diversity within the population [44].

Analysis of the 8 Borrelia strains cultured from $I$. minor larvae and nymphs and reported here showed high heterogeneity among the isolates using different methods of analysis. Previous MLSA of 5 genomic loci of $B$. americana strains separated closely related members into two subgroups, A and B [32]. In this study, combined analysis that involved several methods and 14 genomic loci of SCW-30 strains showed a significant divergence among the strains isolated from 2 developmental stages of $I$. minor, feeding on a single bird. Earlier studies show that if more than one infected tick was collected from a single bird host, all ticks harbour the same spirochete species [83]. Three strains, SCW-30e, SCW30 and SCW-30 g, cultured from I. minor nymphs support this observation, representing diverged strains of the same species. However, analysis of four Borrelia strains isolated from $I$. minor larvae indicated that they were distinct from B. americana and other known spirochete species at majority of genomic loci analyzed. While strains SCW-30b, SCW-30c and SCW-30d clustered together, localization of SCW-30a was incongruent over the whole spectrum of analyzed loci, indicating a probable high level of horizontal genetic exchange among all 8 strains connected to a single bird reservoir host. Even though the recombination does not often occur in a core region of the Borrelia genome [89], a single event of gene conversion was registered in strain SCW-30 h. A nifS gene from $B$. burgdorferi ss, a species that is widely distributed in the United States and Canada, was incorporated into the homologous locus of strain SCW-30 h. This might be possible only in the presence of sympatric genome, either by transmission through a bird host that tick nymphs fed on, or by transmission through the molt stage 
of larvae that fed previously on a host infected with $B$. burgdorferi ss.

A laboratory study of $I$. minor indicated that both nymphs and larvae feed for 4 days on average when fed on laboratory white mice (Mus musculus). Adults were reluctant to feed on the mice, but readily fed on eastern woodrats (Neotoma floridana) [90]. In nature I. minor feeds on a variety of mammals and birds including the cotton mouse, house mouse, cotton rat, cottontail rabbit, eastern rice rat, eastern grey squirrel, eastern spotted skunk, eastern woodrat, and the bird species, Carolina wren, house wren, and the eastern towhee see ref. [90], establishing the possibility of harvesting and amplification of multiple spirochete species.

We have cultured a large number of Borrelia strains from 8 bird species: Carolina wren (Thryothorus ludovicianus), downy woodpecker (Picoides pubescens), whiteeyed vireo (Vireo griseus), Swainson's thrush (Catharus ustulatus), American redstart (Setophaga ruticilla), northern water thrush (Parkesia noveboracensis), pine warbler (Setophaga pinus), and northern cardinal (Cardinalis cardinalis) [91]. Four I. minor nymphs, collected from a Carolina Wren, had a chance to pick up $B$. americana from various hosts during the larval feeding or during their current nymph feeding. I. minor larvae collected from the same bird were feeding for the first time, picking up Borrelia species from the same bird host. It is not unusual that the vector, the reservoir host or LB patient maintain multiple spirochete species [92-99]. However, it is difficult to explain the unprecedented level of diversity among single-bird host-associated spirochete strains, specifically those isolated from larvae, considering the recent claim that transovarial transmission of B. burgdorferi sl does not exist [82].

Our previous studies of LB spirochetes showed very small if any diversity of strains isolated from different vector ticks or rodent hosts, whether it was a group of $B$. burgdorferi ss strains or distinct spirochete species $[31,64,91]$. B. burgdorferi sl species are adapted to hosts and this adaptation is driven by host complement. The dynamics of infection of the host supports the mixing of different genotypes and the horizontal exchange of genetic information. The striking divergence of Borrelia strains associated with a single bird reservoir that we present here supports the earlier hypothesis that vertebrate hosts are the key determinants in the diversity of Lyme disease spirochete [36].

\section{Conclusions}

Genetically diverse Borrelia strains are often found within the same tick or same vertebrate host and this gives a wide opportunity for genetic exchange. We report a case of cross-species recombination that led to the incorporation of an allele of a housekeeping gene from a $B$. burgdorferi sensu stricto strain, the primary causative agent of LB, into the homologous locus of bird-associated strain. Our results add to the recent hypothesis that recombination maintains a majority of sequence polymorphism within Borrelia populations due to re-assortment of pre-existing sequence variants. Even though our findings of increased diversity among 8 strains cultured from ticks that fed on a single bird could be the exception rather than the rule they support the theory that diversity and evolution of LB spirochetes is driven mainly by the host.

\section{Competing interests}

The authors declare that they have no competing interests.

\section{Authors' contributions}

NR and MG designed the experimental scheme and carried complete laboratory work: i.e., strains cultivation and maintenance, DNA purification, PCR amplification and analysis, sequence analysis, RFLP analysis, sequence alignments, results evaluation and drafted the manuscript. NMB conducted phylogenetic analysis, evaluated results, drafted the figures and edited the manuscript. LG designed the study, evaluated results and edited the manuscript. JHO isolated bird-associated samples, cultured SCW-30 strains, evaluated results and drafted the manuscript. All authors read and approved the final version of the manuscript.

\section{Acknowledgements}

This research was supported by GSU Foundation, partially by grant R37Al24899 from the National Institutes of Health, European FP7 project 278976 ANTIGONE (ANTIcipating the Global Onset of Novel Epidemics) and with institutional support RVO:60077344 from Biology Centre, Institute of Parasitology (Czech Republic). We are grateful to Earlene S. Howard of James $\mathrm{H}$. Oliver Jr. Institute of Coastal Plain Sciences for an excellent administrative and technical support of this project.

\section{Author details}

${ }^{1}$ Biology Centre AS CR, Institute of Parasitology, České Budějovice 37005, Czech Republic. ${ }^{2}$ James H Oliver, Jr Institute of Coastal Plain Sciences, Georgia Southern University, Statesboro, GA 30460-8056, USA. ${ }^{3}$ Department of Biology, University of Tampa, Tampa, FL 33606, USA. ${ }^{4}$ University of South Bohemia, České Budějovice 37005, Czech Republic.

Received: 13 November 2013 Accepted: 18 December 2013 Published: 2 January 2014

\section{References}

1. Gern L: Borrelia burgdorferi sensu lato, the agent of Lyme borreliosis: life in the wilds. Parasite 2008, 15:244-247.

2. Anderson JF, Magnarelli LA, Stafford KC 3rd: Bird-feeding ticks trans stadially transmit Borrelia burgdorferi that infect Syrian hamsters. J Wildl Dis 1990, 26:1-10.

3. Manweiler SA, Lane RS, Bloc WM, Morrison ML: Survey of birds and lizards for ixodid ticks (Acari) and spirochetal infection in northern California. J Med Entomol 1990, 27:1011-1015.

4. McLean RG, Ubico SR, Hughes CA, Engstrom SM, Johnson RC: Isolation and characterization of Borrelia burgdorferi from the blood of a bird captured in the Saint Croix River Halley, USA [abstract 235]. Arlington, USA: Proceedings of the Vth International Conference on Lyme Borreliosis; 1992

5. Olsen B, Jaenson TG, Bunikis J, Noppa L, Bergström S: The Lyme borreliosis spirochete found in ticks parasitizing sea birds [abstract 285]. Arlington, USA: Proceedings of the Vth International Conference on Lyme Borreliosis; 1992.

6. Brinkerhoff RJ, Folsom-O'Keefe CM, Tsao K, Diuk-Wasser MA: Do birds affect Lyme disease risk? Range explansion of the vector-borne pathogen Borrelia burgdorferi. Front Ecol Environ 2011, 9:103-110.

7. Norte AC, Ramos JA, Gern L, Núncio MS, Lopes de Carvalho I: Birds as reservoirs for Borrelia burgdorferi s.l. in Western Europe: circulation of $B$. turdi and other genospecies in bird-tick cycles in Portugal. Environ Microbiol 2013, 15:386-397. 
8. Heylen D, Tijsse E, Fonville M, Matthysen E, Sprong H: Transmission dynamics of Borrelia burgdorferi s.l. in a bird tick community. Environ Microbiol 2013, 15:663-673.

9. Ginsberg HS, Buckley PA, Balmforth MG, Zhioua E, Mitra S, Buckley FG Reservoir competence of native North American birds for the lyme disease spirochete, Borrelia burgdorfieri. J Med Entomol 2005, 42:445-449.

10. Rand PW, Lacombe EH, Smith RP, Ficker J: Participation of birds (Aves) in the emergence of Lyme disease in southern Maine. J Med Entomol 1998 35:270-276.

11. Hamer SA, Hickling GJ, Sidge JL, Rosen ME, Walker ED, Tsao Jl: Diverse Borrelia burgdorferi strains in a bird-tick cryptic cycle. App/ Environ Microbiol 2011, 77:1999-2007.

12. Olsen B, Duffy DC, Jaenson TG, Gylfe A, Bonnedahl J, Bergström S: Transhemispheric exchange of Lyme disease spirochetes by seabirds. J Clin Microbiol 1995, 33:3270-3274.

13. Comstedt P, Bergström S, Olsen B, Garpmo U, Marjavaara L, Mejlon H, Barbour AG, Bunikis J: Migratory passerine birds as reservoirs of Lyme borreliosis in Europe. Emerg Infect Dis 2006, 12:1087-1095.

14. Poupon MA, Lommano E, Humair PF, Douet V, Rais O, Schaad M, Jenni L, Gern $L$ : Prevalence of Borrelia burgdorferi sensu lato in ticks collected from migratory birds in Switzerland. Appl Environ Microbiol 2006, 72:976-979.

15. Ogden NH, Lindsay LR, Hanincová K, Barker IK, Bigras-Poulin M, Charron DF Heagy A, Francis CM, O'Callaghan CJ, Schwartz I, Thompson RA: Role of migratory birds in introduction and range expansion of Ixodes scapularis ticks and of Borrelia burgdorferi and Anaplasma phagocytophilum in Canada. Appl Environ Microbiol 2008, 74:1780-1790.

16. Anderson JF, Johnson RC, Magnarelli LA, Hyde FW: Involvement of birds in the epidemiology of the Lyme disease agent Borrelia burgdorferi. Infect Immun 1986, 51:394-396.

17. Hanincová K, Taragelová V, Koci J, Schäfer SM, Hails R, Ullmann AJ, Piesman J, Labuda M, Kurtenbach K: Association of Borrelia garinii and B. valaisiana with songbirds in Slovakia. Appl Environ Microbiol 2003, 69:2825-2830.

18. Baranton G, Postic D, Saint Girons I, Boerlin P, Piffaretti JC, Assous M, Grimont PA: Delineation of Borrelia burgdorferi sensu stricto, Borrelia garinii sp. nov., and group VS461 associated with Lyme borreliosis. Int J Syst Bacteriol 1992, 42:378-383.

19. Canica MM, Nato F, du Merle L, Mazie JC, Baranton G, Postic D: Monoclonal antibodies for identification of Borrelia afzelii sp. nov. associated with late cutaneous manifestations of Lyme borreliosis. Scand J Infect Dis 1993, 25:441-448

20. Chu CY, Liu W, Jiang BG, Wang DM, Jiang WJ, Zhao QM, Zhang PH, Wang ZX, Tang GP, Yang H, Cao WC: Novel genospecies of Borrelia burgdorferi sensu lato from rodents and ticks in southwestern China. J Clin Microbiol 2008, 46:3130-3133.

21. Fukunaga M, Hamase A, Okada K, Nakao M: Borrelia tanukii sp. nov. and Borrelia turdae sp. nov. found from ixodid ticks in Japan: rapid species identification by $16 \mathrm{~S}$ rRNA gene-targeted PCR analysis. Microbiol Immunol 1996, 40:877-881.

22. Kawabata H, Masuzawa T, Yanagihara Y: Genomic analysis of Borrelia japonica sp. nov. isolated from Ixodes ovatus in Japan. Microbiol Immunol 1993, 37:843-848.

23. Le Fleche A, Postic D, Girardet K, Peter O, Baranton G: Characterization of Borrelia lusitaniae sp. nov. by $16 \mathrm{~S}$ ribosomal DNA sequence analysis. Int J Syst Bacteriol 1997, 47:921-925

24. Marconi RT, Liveris D, Schwartz I: Identification of novel insertion elements, restriction fragment length polymorphism patterns, and discontinuous 23S rRNA in Lyme disease spirochetes: phylogenetic analyses of rRNA genes and their intergenic spacers in Borrelia japonica sp. nov. and genomic group 21038 (Borrelia andersonii sp. nov.) isolates. J Clin Microbiol 1995, 33:2427-2434.

25. Margos G, Hojgaard A, Lane RS, Cornet M, Fingerle V, Rudenko N, Ogden N, Aanensen DM, Fish D, Piesman J: Multilocus sequence analysis of Borrelia bissettii strains from North America reveals a new Borrelia species, Borrelia kurtenbachii. Ticks Tick Borne Dis 2010, 1:151-158.

26. Margos G, Vollmer SA, Kornet M, Garnier M, Fingerle V, Wilske B, Bormane A, Vitorino L, Collares-Pereira M, Drancourt M, Kurtenbach K: A new Borrelia species defined by multilocus sequence analysis of housekeeping genes. Appl Environ Microbiol 2009, 75:5410-5416.

27. Masuzawa T, Takada N, Kudeken M, Fukui T, Yano Y, Ishiguro F, Kawamura Y, Imai Y, Ezaki T: Borrelia sinica sp. nov., a Lyme disease-related Borrelia species isolated in China. Int J Syst Evol Microbiol 2001, 51:1817-1824.
28. Postic D, Garnier M, Baranton G: Multilocus sequence analysis of atypical Borrelia burgdorferi sensu lato isolates-description of Borrelia californiensis sp. nov., and genomospecies 1 and 2. Int J Med Microbiol 2007, 297:263-271.

29. Postic D, Ras NM, Lane RS, Hendson M, Baranton G: Expanded diversity among Californian Borrelia isolates and description of Borrelia bissettii sp. nov. (formerly Borrelia group DN127). J Clin Microbio/ 1998, 36:3497-3504.

30. Richter D, Postic D, Sertour N, Livey I, Matuschka FR, Baranton G: Delineation of Borrelia burgdorferi sensu lato species by multilocus sequence analysis and confirmation of the delineation of Borrelia spielmanii sp. nov. Int J Syst Evol Microbiol 2006, 56:873-881.

31. Rudenko N, Golovchenko M, Grubhoffer L, Oliver JH Jr: Borrelia carolinensis sp. nov., a new (14th) member of the Borrelia burgdorferi sensu lato complex from the southeastern region of the United States. J Clin Microbiol 2009, 47:134-141.

32. Rudenko N, Golovchenko M, Lin T, Gao L, Grubhoffer L, Oliver JH Jr: Delineation of a new species of the Borrelia burgdorferi sensu lato complex, Borrelia americana sp. nov. J Clin Microbiol 2009, 47:3875-3880.

33. Wang G, van Dam AP, Le Fleche A, Postic D, Peter O, Baranton G, de Boer R, Spanjaard L, Dankert J: Genetic and phenotypic analysis of Borrelia valaisiana sp. nov. (Borrelia genomic groups VS116 and M19). Int J Syst Bacteriol 1997, 47:926-932.

34. Casjens SR, Fraser-Liggett CM, Mongodin EF, Qiu WG, Dunn JJ, Luft BJ, Schutzer SE: Whole genome sequence of an unusual Borrelia burgdorferi sensu lato isolate. J Bacterio/ 2011, 193:1489-1490.

35. Urwin R, Maiden MC: Multi-locus sequence typing: a tool for global epidemiology. Trends Microbiol 2003, 11:479-487.

36. Kurtenbach K, De Michelis S, Etti S, Schäfer SM, Sewell HS, Brade V, Kraiczy P. Host association of Borrelia burgdorferi sensu lato-the key role of host complement. Trends Microbiol 2002, 10:74-79.

37. Kurtenbach K, De Michelis S, Sewell HS, Etti S, Schäfer SM, Holmes E, Hails R, Collares-Pereira M, Santos-Reis M, Hanincová K, Labuda M, Bormane A, Donaghy M: The key roles of selection and migration in the ecology of Lyme borreliosis. Int J Med Microbiol 2002, 33:152-154.

38. Skerka C, Brade V, Zipfel PF: Further characterization of complement regulator-acquiring surface proteins of Borrelia burgdorferi. Infect Immun 2001, 69:7800-7809.

39. Kraiczy P, Skerka C, Kirschfink M, Zipfel PF, Brade V: Mechanism of complement resistance of pathogenic Borrelia burgdorferi isolates. Int Immunopharmacol 2001, 1:393-401.

40. Kurtenbach K, Schäfer SM, Sewell HS, Peacey M, Hoodless A, Nuttall PA, Randolph SE: Differential survival of Lyme borreliosis spirochetes in ticks that feed on birds. Infect Immun 2002, 70:5893-5895.

41. Stevenson B, El-Hage N, Hines MA, Miller JC, Babb K: Differential binding of host complement inhibitor factor $\mathrm{H}$ by Borrelia burgdorferi Erp surface proteins: a possible mechanism underlying the expansive host range of Lyme disease spirochetes. Infect Immun 2002, 70:491-497.

42. Eggers CH, Kimmel BJ, Bono JL, Elias AF, Rosa P, Samuels DS: Transduction by phiBB-1, a bacteriophage of Borrelia burgdorferi. J Bacteriol 2001, 183:4771-4778.

43. Kurtenbach K, Hanincová K, Tsao Il, Margos G, Fish D, Ogden NH: Fundamental processes in the evolutionary ecology of Lyme borreliosis. Nat Rev Microbiol 2006, 4:660-669.

44. Brisson D, Dykhuizen DE: ospC diversity in Borrelia burgdorferi: different hosts are different niches. Genetics 2004, 168:713-722.

45. Brisson D, Vandermause MF, Meece JK, Reed KD, Dykhuizen DE: Evolution of northeastern and midwestern Borrelia burgdorferi, United States. Emerg Infect Dis 2010, 16:911-917.

46. Guttman DS, Wang PW, Wang IN, Bosler EM, Luft BJ, Dykhuizen DE: Multiple infections of Ixodes scapularis ticks by Borrelia burgdorferi as revealed by single-strand conformation polymorphism analysis. J Clin Microbiol 1996, 34:652-656.

47. Haven J, Vargas LC, Mongodin EF, Xue V, Hernandez Y, Pagan P, Fraser-Liggett CM, Schutzer SE, Luft BJ, Casjens SR, Qiu WG: Pervasive recombination and sympatric genome diversification driven by frequency-dependent selection in Borrelia burgdorferi, the Lyme disease bacterium. Genetics 2011, 189:951-966.

48. Postic D, Assous MV, Grimont PA, Baranton G: Diversity of Borrelia burgdorferi sensu lato evidenced by restriction fragment length polymorphism of rrf (5S)-rrl (23S) intergenic spacer amplicons. Int J Syst Bacteriol 1994, 44:743-752. 
49. Güner ES, Hashimoto N, Takada N, Kaneda K, Omak Y, Masuzawa T: First isolation and characterization of Borrelia burgdorferi sensu lato strains from Ixodes ricinus ticks in Turkey. J Med Microbiol 2003, 52:807-813.

50. Clark K, Hendricks A, Burge D: Molecular identification and analysis of Borrelia burgdorferi sensu lato in lizards in the southeastern United States. Appl Environ Microbiol 2005, 71:2616-2625.

51. Bunikis J, Garpmo U, Tsao J, Berglund J, Fish D, Barbour AG: Sequence typing reveals extensive strain diversity of the Lyme borreliosis agents Borrelia burgdorferi in North America and Borrelia afzelii in Europe. Microbiology 2004, 150:1741-1755.

52. Margos G, Gatewood AG, Aanensen DM, Hanincová K, Terekhova D, Vollmer SA, Cornet M, Piesman J, Donaghy M, Bormane A, Hurn MA, Feil EJ, Fish D, Casjens S, Wormser GP, Schwartz I, Kurtenbach K: MLST of housekeeping genes captures geographic population structure and suggests a European origin of Borrelia burgdorferi. Proc Natl Acad Sci USA 2008, 105:8730-8735.

53. Bikandi J, San Millán R, Rementeria A, Garaizar J: In silico analysis of complete bacterial genomes: PCR, AFLP-PCR and endonuclease restriction. Bioinformatics 2004, 20:798-799.

54. Hoogstraal $\mathrm{H}$ : Birds as tick hosts and as reservoirs and disseminators of tickborne infectious agents. Wiad Parazytol 1972, 18:703-706.

55. Larkin MA, Blackshields G, Brown NP, Chenna R, McGettigan PA, McWilliam H, Valentin F, Wallace IM, Wilm A, Lopez R, Thompson JD, Gibson TJ, Higgins DG: Clustal W and Clustal X version 2.0. Bioinformatics 2007, 23:2947-2948

56. Nylander JAA: MrModeltest v2.3. Program distributed by the author. Uppsala, Sweden: Evolutionary Biology Centre: Uppsala University; 2008.

57. Akaike $\mathrm{H}$ : A new look at the statistical model identification. IEEE Trans Autom Contr 1974, 19:716-723.

58. Huelsenbeck JP, Ronquist F, Nielsen R, Bollback JP: Bayesian inference of phylogeny and its impact on evolutionary biology. Science 2001, 294:2310-2314.

59. Ronquist F, Huelsenbeck JP: MrBayes 3: Bayesian phylogenetic inference under mixed models. Bioinformatics 2003, 19:1572-1574

60. Nylander JAA, Wilgenbusch JC, Warren DL, Swofford DL: AWTY (are we there yet?): a system for graphical exploration of MCMC convergence in Bayesian phylogenetics. Bioinformatics 2008, 24:581-583.

61. Larget BR, Kotha SK, Dewey CN, Ané C: BUCKy: gene tree/species tree reconciliation with Bayesian concordance analysis. Bioinformatics 2010 26:2910-2911.

62. Allman ES, Degnan JH, Rhodes JA: Identifying the rooted species tree from the distribution of unrooted gene trees under the coalescent. J Math Biol 2011, 62:833-862.

63. Ané C, Larget B, Baum DA, Smith SD, Rokas A: Bayesian estimation of concordance among gene trees. Mol Biol Evol 2007, 24:412-426.

64. Rudenko N, Golovchenko M, Hönig V, Mallátová N, Krbková L, Mikulásek P, Fedorova N, Belfiore NM, Grubhoffer L, Lane RS, Oliver JH Jr: Detection of Borrelia burgdorferi sensu stricto ospC alleles associated with human Lyme borreliosis worldwide in non-human-biting tick Ixodes affinis and rodent hosts in southeastern United States. Appl Environ Microbiol 2013, 79:1444-1453.

65. Aanensen DM, Spratt BG: The multilocus sequence typing network: mlst. net. Nucleic Acids Res 2005, 33(Web Server issue):W728-W733.

66. Margos G, Vollmer SA, Ogden NH, Fish D: Population genetics, taxonomy, phylogeny and evolution of Borrelia burgdorferi sensu lato. Infect Genet Evol 2011, 11:1545-1563.

67. Qiu WG, Dykhuizen DE, Acosta MS, Luft BJ: Geographic uniformity of the Lyme disease spirochete (Borrelia burgdorferi) and its shared history with tick vector (Ixodes scapularis) in the northeastern United States. Genetics 2002, 160:833-849.

68. Wang IN, Dykhuizen DE, Qiu W, Dunn JJ, Bosler EM, Luft BJ: Genetic diversity of ospC in a local population of Borrelia burgdorferi sensu stricto. Genetics 1999, 151:15-30.

69. Brisson D, Dykhuizen DE: A modest model explains the distribution and abundance of Borrelia burgdorferi strains. Am J Trop Med Hyg 2006, 74:615-622.

70. Brinkerhoff RJ, Bent SJ, Folsom-O'Keefe CM, Tsao K, Hoen AG, Barbour AG, Diuk-Wasser MA: Genotypic diversity of Borrelia burgdorferi strains detected in Ixodes scapularis larvae collected from North American songbirds. Appl Environ Microbiol 2010, 76:8265-8268.

71. Humair PF, Postic D, Wallich R, Gern L: An avian reservoir (Turdus merula) of the Lyme borreliosis spirochetes. Zentralb/ Bakteriol 1998, 287:521-538.
72. Ishiguro F, Takada N, Masuzawa T, Fukui T: Prevalence of Lyme disease Borrelia spp. in ticks from migratory birds on the Japanese mainland. Appl Environ Microbiol 2000, 66:982-986.

73. Kurtenbach K, Peacey M, Rijpkema SG, Hoodless AN, Nuttall PA, Randolph SE: Differential transmission of the genospecies of Borrelia burgdorferi sensu lato by game birds and small rodents in England. Appl Environ Microbiol 1998, 64:1169-1174.

74. Miyamoto K, Nakao M, Fujita H, Sato F: The Ixodid ticks on migratory birds in Japan and the isolation of Lyme disease spirochetes from bird-feeding ticks. Jpn J Sanit Zool 1993, 44:315-326.

75. Miyamoto K, Sato Y, Okada K, Fukunaga M, Sato F: Competence of a migratory bird, red-bellied thrush (Turdus chrysolaus), as an avian reservoir for the Lyme disease spirochetes in Japan. Acta Trop 1997, 65:43-51.

76. Nakao M, Miyamoto K, Fukunaga M: Lyme disease spirochetes in Japan: enzootic transmission cycles in birds, rodents, and lxodes persulcatus ticks. J Infect Dis 1994, 170:878-882.

77. Smith RP Jr, Rand PW, Lacombe EH, Morris SR, Holme DW, Caporale DA: Role of bird migration in the long-distance dispersal of Ixodes dammini, the vector of Lyme disease. J Infect Dis 1996, 174:221-224.

78. Weisbrod AR, Johnson RC: Lyme disease and migrating birds in the Saint Croix River Valley. Appl Environ Microbiol 1989, 55:1921-1924.

79. Morshed MG, Scott JD, Fernando K, Beati L, Mazerolle DF, Geddes G, Durden LA: Migratory songbirds disperse ticks across Canada, and first isolation of the Lyme disease spirochete, Borrelia burgdorferi, from the avian tick, Ixodes auritulus. J Parasitol 2005, 91:780-790.

80. Humair PF, Turrian N, Aeschlimann A, Gern L: Ixodes ricinus immatures on birds in a focus of Lyme borreliosis. Folia Parasitol (Praha) 1993, 40:237-242.

81. Olsén B, Jaenson TG, Bergström S: Prevalence of Borrelia burgdorferi sensu lato-infected ticks on migrating birds. Appl Environ Microbiol 1995, 61:3082-3087.

82. Rollend L, Fish D, Childs JE: Transovarial transmission of Borrelia spirochetes by Ixodes scapularis: a summary of the literature and recent observations. Ticks Tick Borne Dis 2013, 4:46-51.

83. Kipp S, Goedecke A, Dorn W, Wilske B, Fingerle V: Role of birds in Thuringia, Germany, in the natural cycle of Borrelia burgdorferi sensu lato, the Lyme disease spirochaete. Int J Med Microbio/ 2006, 40(296):125-128.

84. Yuval B, Spielman A: Duration and regulation of the developmental cycle of Ixodes dammini (Acari: Ixodidae). J Med Entomol 1990, 27:196-201.

85. Kuo MM, Lane RS, Giclas PC: A comparative study of mammalian and reptilian alternative pathway of complement-mediated killing of the Lyme disease spirochete (Borrelia burgdorferi). J Parasitol 2000, 86:1223-1228.

86. Lane RS, Quistad GB: Borreliacidal factor in the blood of the western fence lizard (Sceloporus occidentalis). J Parasitol 1998, 84:29-34.

87. Nelson DR, Rooney S, Miller NJ, Mather TN: Complement-mediated killing of Borrelia burgdorferi by non-immune sera from sika deer. J Parasitol 2000, 86:1232-1238.

88. Van Dam AP, Oei A, Jaspars R, Fijen C, Wilske B, Spanjaard L, Dankert J: Complement-mediated serum sensitivity among spirochetes that cause Lyme disease. Infect Immun 1997, 65:1228-1236.

89. Morlon H, Kemps BD, Plotkin JB, Brisson D: Explosive radiation of a bacterial species group. Evolution 2012, 66:2577-2586.

90. Banks CW, Oliver JH Jr, Philips JB, Clark KL: Life cycle of Ixodes minor (Acari: Ixodidae) in the laboratory. J Med Entomol 1998, 35:496-499.

91. Rudenko N, Golovchenko M, Grubhoffer L, Oliver JH Jr: The rare ospC allele L of Borrelia burgdorferi sensu stricto, commonly found among samples collected in a coastal plain area of the southeastern United States, is associated with Ixodes affinis ticks and local rodent hosts Peromyscus gossypinus and Sigmodon hispidus. Appl Environ Microbiol 2013, 79:1403-1406.

92. Beklemishev AB, Dobrotvorsky AK, Piterina AV, Ivanov ID, Nomokonova NY, Livanova NN: Detection and typing of Borrelia burgdorferi sensu lato genospecies in Ixodes persulcatus ticks in West Siberia, Russia. FEMS Microbiol Lett 2003, 227:157-161.

93. Chu CY, He J, Wang JB, Hasen GW, Zhang PH, Wu XM, Zhao QM, Jiang BG, Gao Y, Cao WC: Investigation on Borrelia burgdorferi sensu lato in ticks and rodents collected in Da Xing-An Mountains Forest areas of China. Zhonghua Liu Xing Bing Xue Za Zhi 2006, 27:681-684.

94. Demaerschalck I, Ben Messaoud A, De Kesel M, Hoyois B, Lobet $Y$, Hoet $P$, Bigaignon G, Bollen A, Godfroid E: Simultaneous presence of different 
Borrelia burgdorferi genospecies in biological fluids of Lyme disease patients. J Clin Microbiol 1995, 33:602-608.

95. Fichet-Calvet E, Jomâa I, Ben Ismail R, Ashford RW: Patterns of infection of haemoparasites in the fat sand rat, Psammomys obesus, in Tunisia, and effect on the host. Ann Trop Med Parasitol 2000, 94:55-68.

96. Oksi J, Marjamäki M, Koski K, Nikoskelainen J, Viljanen MK: Bilateral facial palsy and meningitis caused by Borrelia double infection. Lancet 1995, 345:1583-1584.

97. Rudenko N, Golovchenko M, Rưzek D, Piskunova N, Mallátová N, Grubhoffer $\mathrm{L}$ : Molecular detection of Borrelia bissettii DNA in serum samples from patients in the Czech Republic with suspected borreliosis. FEMS Microbiol Lett 2009, 292:274-281.

98. Rudenko N, Golovchenko M, Nemec J, Volkaert J, Mallátová N, Grubhoffer L: Improved method of detection and molecular typing of Borrelia burgdorferi sensu lato in clinical samples by polymerase chain reaction without DNA purification. Folia Microbiol (Praha) 2005, 50:31-39.

99. Vennestrøm J, Egholm H, Jensen PM: Occurrence of multiple infections with different Borrelia burgdorferi genospecies in Danish Ixodes ricinus nymphs. Parasitol Int 2008, 57:32-37.

doi:10.1186/1756-3305-7-4

Cite this article as: Rudenko et al:: Divergence of Borrelia burgdorferi sensu lato spirochetes could be driven by the host: diversity of Borrelia strains isolated from ticks feeding on a single bird. Parasites \& Vectors 2014 7:4.

\section{Submit your next manuscript to BioMed Central and take full advantage of:}

- Convenient online submission

- Thorough peer review

- No space constraints or color figure charges

- Immediate publication on acceptance

- Inclusion in PubMed, CAS, Scopus and Google Scholar

- Research which is freely available for redistribution 